\section{FOUR EYEOPENER BOOKS AND ONE DEPRESSING ADDICTION: APPLY THE LOGIC OF SELF-DESTRUCTION TO UNDERSTAND THE LOGIC OF MADNESS WHEN CHASING THE SCREAMIS WORSENING LOST CONNECTIONS}

To the editor:

It has been mesmerizing that on one hand, living things are born with the instinct to exist no matter what and yet the same living things evolve the instinct to selfdestruct no matter what. The core question is why. The simple answer is why not. The birth of a living body and its consciousness inside the matrix is chained to the events pre-existing before the said births. These chains are genetic and environmental which keep on adding some new chains while subtracting some old chains with each birth into the matrix. To understand the instinct to exist and yet to self-destruct as ambiguity at best and as bizarre at worst, one has to understand the cumulative experience of evolution imprinted on a body and its consciousness even before its birth. Simply stating, to make sense out of nonsensical existence in the matrix, one has to understand instincts' implications in the past which have shaped the currently born body and its consciousness as well as instincts' implications in the future which will decide what it will be like to be a born body and its consciousness in the future. The bottom-line is that a living thing and its consciousness is existing in the matrix because without the instinct to exist, the living thing and its consciousness won't have existed in the first place. Simplistically, only those with the instinct to exist have continued to exist in the matrix while those with the instinct to self-destruct had ceased to exist long time ago or will cease to exist in due course of time. However, the existence within the matrix is not as simple as that because the so-called "immortal" selfish gene is pervasively present in all living things. ${ }^{1}$ Herein, bodies are born with amalgamation of both types of instincts whereby depending on bodies' adaptations to their environments, all bodies variably express genes in variable ratios to exist as well as to self-destruct thus creating the bizarre ambiguities to exist as well as to self-destruct at the same time. Now the question arises whether the instinct to self-destruct contributes anything to the instinct to exist in living thing or its consciousness because there is a logic to this madness as eloquently described by theorist, Matthew
Blakeway, in his two books, The Logic of SelfDestruction: The Algorithm of Human Rationality and The Logic of Madness: A New Theory of Mental Illness., ${ }^{2,3}$ However, the story does not end there. My awakening to these two books' content has been furthered by the writings of journalist, Johann Hari, in his two books, Chasing the Scream: The First and Last Days of the War on Drugs and Lost Connections: Uncovering the Real Causes of Depression — and the Unexpected Solutions. ${ }^{4,5}$

Having become an ardent fan of both these authors, I will not dilute the powerful effect of their books by writing their reviews because they have to be read to be understood and to be believed. If it is difficult to intrigue readers into reading them, the readers can start by delving into Matthew Blakeway's books' reviews by Claire M. Fletcher-Flinn and the audience can start by delving into Johann Hari's TED Talks about his books. ${ }^{6-9}$ In a nutshell, these four books tell us why we are where we are and try to inculcate how we can go on from where we are to where we can be unless we only want to reflect in the retrospect from wherever we will be.

These are just some of my humble personal interpretations about how these four books make me rethink about addiction and depression: ${ }^{10,11}$

- Is connectedness via virtuality interfering with healthy humanity's connectedness to itself?

- As humans are not lonely lions unless they may evolve to be in dystopic future, are humans (bees) missing their tribes (hives) in the present times?

- Does the adversarial system work for adversaries or for collaterals or for neither?

- How does society expect to overcome addiction by worsening isolation for those with addiction?

- Are humans creating demons by first prohibiting whatever innately human then regulating whatever mistaken demon to finally normalizing whatever pathetic confusion ? $^{12}$

- Can humans control overabundance by prohibition? Can humans correct prohibition by 
regulation? Can humans prevent regulation becoming normalization?

- Will corporatization of normal be better for society than criminalization of abnormal when neither corporatization nor criminalization can overcome or even control overabundance?

- Should humanity apologize for its urge to survive when virtuality is not apologizing for its titanically growing urge to flourish?

- Just like animals, why is it innate in humans to be cheaters turning easily into suckers rather than becoming grudgers who are needed the most to evolve and ensure fair and just societies?

- Why do humans mistake their innate objective calculations as calculated subjective choices?

- Is memory a ghost inside the mind which itself is claimed to be a ghost inside the machine called human?

- Did ancestors with truly self-destructive genes not leave behind any surviving descendants?

- Are so-called self-destructive descendants actually trying to survive but their survival instincts have maladapted with self-destructive behaviors?

- Should humans seek to find purpose of life? Or must humans invent purpose of life as in the truest essence there is no purpose of life and such knowledge of truth can be apocalyptically depressing?

- Is "self" an invention by the ghost called mind inside the machine called human? And is "destruction" evolution of one machine (in part or as whole) into another machine (in part or as whole)? And is perception of "self-destruction" a construct that is de-constructed and thence re-constructed by the ghost called mind inside the machine called human?

- Is happiness an invention by humans when in the truest sense at least for animals, happiness may be just the absence of distress (sadness)?
Summarily, after reading the above-mentioned four books as eyeopeners as if relishing Four Weddings and a Funeral, ${ }^{13}$ I am confident that readers may be able to explore, recognize, accept and address depressing addiction and/or addicting depression as maladaptation in lives primarily needing changes to lives rather than only as chronically relapsing diseases solely and sorely needing more pills to correct the faults in prior trials of failed pills.

\section{Deepak Gupta, MD \\ Clinical Assistant Professor, Anesthesiology \\ Wayne State University \\ Detroit, Michigan}

\section{REFERENCES}

1. Dawkins R: Richard Dawkins-The Selfish Gene explained. Available at: https://www youtube.com/watch? v=j9p2F2oaO_k. Accessed October 17, 2021.

2. Blakeway M: The Logic of Self-Destruction: The Algorithm of Human Rationality. Available at: https://www.amazon.com/ Logic-Self-Destruction-Algorithm-Human-Rationalityebook/dp/BOOKEBFKUU. Accessed October 17, 2021.

3. Blakeway M: The Logic of Madness: A New Theory of Mental Illness. Available at: https://www.amazon.com/Logic-MadnessTheory-Illness-Self-Destruction-ebook/dp/BO1DONG9MC. Accessed October 17, 2021.

4. Hari J: Chasing the Scream: The First and Last Days of the War on Drugs. Available at: https://www.amazon.com/gp/product/ BOOOZM4ANM. Accessed October 17, 2021.

5. Hari J: Lost Connections: Uncovering the Real Causes of Depression - and the Unexpected Solutions. Available at: https://www.amazon.com/gp/product/B07583XJRW. Accessed October 17, 2021.

6. Fletcher-Flinn CM: Beliefs, self-destruction, and the rational mind. Frontiers in Psychology. 2014; 5: 1231. DOI: https:// doi.org/10.3389/fpsyg.2014.01231. Available at: https:// www. frontiersin.org/articles/10.3389/fpsyg.2014.01231/full. Accessed October 17, 2021.

7. Fletcher-Flinn CM: Book review: The Logic of Madness: A New Theory of Mental Illness. Frontiers in Psychology. 2016; 7: 946. DOI: 10.3389/fpsyg.2016.00946. Available at: bttps:// www frontiersin.org/articles/10.3389/fpsyg.2016.00946/full. Accessed October 17, 2021.

8. Hari J: Everything you think you know about addiction is wrong. Available at: https://www youtube.com/watch?v= PY9DcIMGXMs. Accessed October 17, 2021.

9. Hari J: This could be why you're depressed or anxious. Available at: https://www youtube.com/watch? $=M B 5 I X-n p 5 f E$. Accessed October 17, 2021.

10. Twitter search: andgandg matthewblakeway. Available at: https://twitter.com/search?q=andgandg\%20matthewblakeway $\xi s r c=$ typed_query $\xi f=$ live. Accessed October 17, 2021.

11. Twitter search: andgandg johannhari101. Available at: https://twitter.com/search?q=andgandg\%20johannhari101Esrc =typed_query $\& f=l i v e$. Accessed October 17, 2021.

12. Gupta D: Health Care Infinity: Prohibit Regulate Normalize. WebmedCentral ECONOMICS OF MEDICINE 2021; 12(4): WMC005697. Available at: https://www.webmedcentral.com/ article_view/5697. Accessed October 17, 2021.

13. IMDb: Four Weddings and a Funeral. Available at: https:// www.imdb.com/title/tt0109831/. Accessed October 17, 2021. 